Cite this: Metallomics, 2013, 5, 1285

Received 28th March 2013, Accepted 2nd July 2013

DOI: $10.1039 / \mathrm{c} 3 \mathrm{mt} 00101 \mathrm{f}$

www.rsc.org/metallomics

\title{
Identification of the tri-Al tricitrate complex in Plantago almogravensis by hydrophilic interaction LC with parallel ICP-MS and electrospray Orbitrap MS/MS detection $\dagger$
}

\author{
Tomás Grevenstuk, ${ }^{a}$ Paulina Flis, ${ }^{\mathrm{b}}$ Laurent Ouerdane, ${ }^{\mathrm{b}}$ Ryszard Lobinski ${ }^{\mathrm{bc}}$ and \\ Anabela Romano*a
}

\begin{abstract}
The identification of the ligands binding $\mathrm{Al}$ is essential to understand the mechanisms by which plants detoxify Al internally. However, studies concerning the speciation of Al have been frustrated by its complex chemistry. This work describes the identification of the tri-Al tricitrate $\left(\mathrm{Al}_{3} \mathrm{Cit}_{3}\right)$ complex in Plantago almogravensis, encompassing an integrated mass spectrometry approach based on hydrophilic interaction liquid chromatography (HILIC) and parallel detection by ICP-MS and ESI-MS/MS. This work also reports that both $\mathrm{Al}$ and $\mathrm{Fe}$ are bound by tricitrate, sometimes simultaneously, and the consequences of this finding are discussed. Of the complexes separated by size exclusion chromatography, $\mathrm{Al}_{3} \mathrm{cit}_{3}$ is the most stable occurring in P. almogravensis as it was the only one recovered after HILIC. This approach provided new information on the mechanism of Al detoxification in $P$. almogravensis, namely that $\mathrm{Al}$ is bound by the organic acid citrate and that the relative concentration of the detected complexes is affected by the organ type and internal Al concentration, and has potential for studying the speciation of $\mathrm{Al}$ in less tolerant plants.
\end{abstract}

\section{Introduction}

Aluminium (Al) toxicity is one of the most serious limitations to plant growth in acidic soils. Most $\mathrm{Al}$ exists as oxides and aluminosilicates, which are harmless to plants; however, in acidic soils, $\mathrm{Al}$ is solubilized as the trivalent cation $\mathrm{Al}^{3+}$. The precise targets at molecular and cellular levels remain elusive but it is known that free Al rapidly inhibits root growth and limits the subsequent uptake of water and nutrients. ${ }^{1}$ The relevance of $\mathrm{Al}$ toxicity is aggravated by the fact that $\mathrm{Al}$ is the third most abundant element in the Earth's crust and that approximately $30 \%$ of the world's total ice-free land has a $\mathrm{pH}<$ 5.5. ${ }^{2}$ However, some plants are capable of performing despite taking up $\mathrm{Al}$ from soils. This occurrence is intriguing because even knowing that only a small percentage of $\mathrm{Al}$ is in its free

\footnotetext{
${ }^{a}$ IBB-CGB, Faculty of Sciences and Technology, University of Algarve, Campus de Gambelas, 8005-139 Faro, Portugal. E-mail: aromano@ualg.pt

${ }^{b}$ CNRS/UPPA, Laboratoire de Chimie Analytique Bio-inorganique et Environnement, UMR 5254, Helioparc, 2, Av. Pr. Angot, 64053 Pau, France

${ }^{c}$ Chair of Analytical Chemistry, Warsaw University of Technology,

00-664 Warszawa, Poland

† Electronic supplementary information (ESI) available. See DOI: 10.1039/ c3mt00101f
}

state at physiological $\mathrm{pH}$, such low concentrations can still be phytotoxic because of the strong affinity of $\mathrm{Al}$ for oxygen donor ligands. ${ }^{3}$ Plantago almogravensis Franco thrives in soils with high free $\mathrm{Al}$ concentrations and its geographical distribution is restricted to a small area (10 ha) located at the SW of the Iberian Peninsula ${ }^{4}$ and has thus been included in the UICN-Red List of critically endangered species. ${ }^{5}$ P. almogravensis is known to accumulate $\mathrm{Al}^{4,6}$ however, the complexes that bind $\mathrm{Al}$ internally and thus protect vital biochemical processes are unknown.

Even if, to date, ${ }^{27} \mathrm{Al}$ nuclear magnetic resonance (NMR) spectroscopy has been used almost exclusively to study the speciation of $\mathrm{Al}$ in plants, as it can provide structural information about Al-complexes directly from intact samples, the inherent low sensitivity and low discriminating capacity of NMR spectroscopy for $\mathrm{Al}$ is a drawback that has prevented accurate speciation. ${ }^{7}$ Mass spectrometry using electrospray ionization (ESI-MS) is a technique that offers increased sensitivity and great potential for identification of metal complexes but has found little application in the field of Al-speciation due to the lack of a suitable isotope. Because of the gentle transition from solution to the gas phase and the low collision energies, the dissociation of metal complexes is less likely and singly-charged 
species with high mass resolution are generally produced, yielding simple mass spectra that facilitate assignment. ${ }^{8}$ The lack of an isotope to aid with localization of Al-bearing complexes in mass spectra can be circumvented by parallel detection with an elemental detection technique, such as inductively coupled plasma (ICP)-MS, which allows determining the retention times of $\mathrm{Al}$-complexes and pinpointing the region of the MS chromatogram that should be examined. Biological samples are too complex for direct infusion or flow injection, so chromatographic separation prior to ESI-MS measurements is required. Chromatography can pose a hurdle to the identification of Al-complexes because they can be dissociated as a result of the interaction with the stationary phase and the buffer content of the mobile phase can suppress ionization efficiency. These interactions are minimized when using size-exclusion chromatography (SEC) columns and hydrophilic interaction chromatography (HILIC) columns (that allow proper retention of highly polar complexes) and their corresponding buffers are compatible with ESI-MS.

The goal of this work is to study the speciation of $\mathrm{Al}$ in $P$. almogravensis plants to determine the ligands responsible for detoxifying Al using an MS-based approach. A previously established experimental design using in vitro produced plants $^{6 a}$ was employed to eliminate extraneous factors and determine the intrinsic detoxification capacity of $P$. almogravensis without compromising natural populations.

\section{Experimental}

\section{Reagents and standards}

Analytical reagent grade chemicals such as acetonitrile, formic acid, acetic acid, nitric acid, ammonium acetate and ammoniac were purchased from Sigma-Aldrich (Saint-Quentin-Fallavier, France), metal standards from SCP Science (Canada) and citric acid from Acros Organics (Belgium). Ultrapure water (18 $\mathrm{M} \Omega \mathrm{cm}^{-1}$ ) was obtained from a Milli-Q system (Millipore, Bedford, MA).

\section{Plant material and Al-treatment}

Shoots of a selected $P$. almogravensis genotype were separated from in vitro axenic cultures proliferating for 6 weeks in Murashige and Skoog's medium ${ }^{9}$ supplemented with 6-benzyladenine at $0.2 \mathrm{mg} \mathrm{L}^{-1} \cdot{ }^{10}$ The obtained shoots were transferred to Murashige and Skoog's medium with macronutrients reduced to half containing $0.5 \mathrm{mg} \mathrm{L}^{-1}$ indole-3-acetic acid to induce root development. The produced plantlets were transferred aseptically to autoclaved Murashige and Skoog's liquid medium with macronutrients reduced to one quarter at $\mathrm{pH} 4.0$ supplemented with 100,200 or $400 \mu \mathrm{M}$ Al for a 7-day treatment according to Martins et al. ${ }^{6 a}$ The chemical speciation program Geochem-EZ (http://www.plantmineralnutrition.net/Geochem/ geochem\%20home.htm) ${ }^{11}$ was used to predict the $\mathrm{Al}^{3+}$ and $\mathrm{Fe}^{3+}$ activity values and $\mathrm{Al}$ and $\mathrm{Fe}$ speciation for each nutrient solution based on chemical equilibrium constants. In order to study the role of roots in the formation of Al-complexes, shoots without developed root system were also subjected to Al-treatment.
The cultures were maintained at $25 \pm 2{ }^{\circ} \mathrm{C}$ with a $16 \mathrm{~h}$ photoperiod (cool white fluorescent lamps, $69 \mu \mathrm{mol} \mathrm{m}{ }^{-2} \mathrm{~s}^{-1}$ ). Samples of fresh leaves, roots and shoots $(\sim 20 \mathrm{mg})$ were placed in eppendorfs, frozen in liquid nitrogen and ground with a glass rod. Extraction was carried out by adding $100 \mu \mathrm{L}$ of water and mechanically stirring for $2 \mathrm{~min}$ at room temperature followed by centrifugation (3 $\mathrm{min}, 14500 \mathrm{rpm}$ ). The supernatants were collected and immediately analysed. Apart from biological samples, standard solutions of Al-citric and -oxalic acid (3:1 ratio of organic acid to $\mathrm{Al}$, buffered at $\mathrm{pH}$ 6) at an $\mathrm{Al}$ concentration approximate to that of roots were prepared for speciation analysis.

\section{SEC-ICP-MS experiments}

The SEC separations were conducted with a Dionex UltiMate 3000 LC-system (Thermo Fisher Scientific, Bremen, Germany) coupled to a 7500cs ICP-MS instrument (Agilent) equipped with a collision cell with hydrogen as collision gas. The interface between the LC system and the ICP-MS detector consisted of a quartz double pass Scott style spray chamber, a MicroMist EzyFit nebulizer (Glass Expansion, Australia), a $2.5 \mathrm{~mm}$ i.d. quartz torch and a set of nickel cones (Agilent Technologies, USA). The undiluted plant extracts and standard solutions $(10 \mu \mathrm{L})$ were injected onto a Superdex Peptide HR 10/30 $(300 \times 10 \mathrm{~mm}$ i.d.; GE Healthcare Bio-Science AB, Sweden $)$ SEC column using $5 \mathrm{mM}$ ammonium acetate buffer at $\mathrm{pH} 6.2$ as a mobile phase at a flow rate of $0.7 \mathrm{~mL} \mathrm{~min}^{-1}$. The ICP-MS conditions were optimized daily for highest intensities and lowest interferences using a standard built-in software procedure. The $\mathrm{H}_{2}$ collision cell mode was used to exclude polyatomic interferences that may occur for $\mathrm{Fe}$ and $\mathrm{Al}$ isotopes.

\section{HILIC-ICP-MS/ESI-MS/MS experiments}

The HILIC separations were performed using an Agilent 1100 capillary pump (Agilent, Tokyo, Japan) as a delivery system equipped with a $100 \mu \mathrm{L} \min ^{-1}$ splitter module. The HILIC column was a TSK gel amide $80(250 \times 1 \mathrm{~mm}$ i.d.) (Tosoh Bioscience, Germany). The binary mobile phase consisted of (A) $10 \mathrm{mmol} \mathrm{L}{ }^{-1}$ ammonium formate buffer at $\mathrm{pH} 5.5$ and (B) acetonitrile. The optimized HILIC gradient started with $10 \%$ of A and was increased to $50 \%$ of A in $45 \mathrm{~min}$. Samples were diluted with acetonitrile to obtain a 1 to 2 ratio (sample : acetonitrile), centrifuged and $7 \mu \mathrm{L}$ of the supernatant was analyzed at the flow rate of $50 \mu \mathrm{L} \mathrm{min}{ }^{-1}$. The HPLC unit was coupled either to an ICP-MS or an ESI-MS/MS instrument. The interface between the LC module and the ICP-MS detector consisted of a glass Cinnabar cyclonic spray chamber (Glass Expansion, Australia), a $50 \mu \mathrm{L} \mathrm{min}^{-1}$ Micromist U-series nebulizer (Glass Expansion, Australia), a $1 \mathrm{~mm}$ i.d. injector torch (Agilent Technologies, Japan), a T-connector allowing the introduction of $11 \% \mathrm{O}_{2}$ and a set of platinum cones (Agilent Technologies, USA). The ICP MS conditions were optimized in the same way as for SEC-ICP-MS measurements. The ESI-MS/MS instrument was an LTQ Orbitrap Velos mass spectrometer (Thermo Fisher Scientific, Bremen, Germany) equipped with a heated electrospray ionization source (H-ESI II) (Thermo Fisher Scientific). 
The instrument was operated in the positive ion mode with the electrospray voltage set at $3 \mathrm{kV}$. The source and capillary temperature were $120{ }^{\circ} \mathrm{C}$ and $280{ }^{\circ} \mathrm{C}$, respectively. The ESI-MS spectra were obtained in the $150-1200 \mathrm{~m} / \mathrm{z}$ range with the resolution set at 100000 . The ions were fragmented by collision-induced dissociation (CID) at the energy level of $45 \%$.

\section{Total metal concentration determination}

Triplicates of dried leaf and shoot samples were ground with a pestle and mortar, digested in $70 \%$ nitric acid for $6 \mathrm{~h}$ at $65{ }^{\circ} \mathrm{C}$ and then diluted before analysis 10 times with $2 \% \mathrm{HNO}_{3}$. The acidified sample and standard solution of metallic elements were analysed by ICP-MS (Agilent 7500ce, Tokyo, Japan).

\section{Results}

Analysis of $P$. almogravensis samples exposed to Al by SEC-ICPMS allowed for the separation of five Al species numbered according to elution time (Fig. 1). The same complexes were observed in root and leaf samples of plants grown under controlled conditions exposed to $400 \mu \mathrm{M} \mathrm{Al}$, albeit at lower concentrations in leaves (Fig. 1A). However, when plantlets with excised root systems (shoots) were subjected to the same concentration of $\mathrm{Al}$, the complexes 1 to 4 could not be observed. Instead, a poorly resolved broad signal was detected at longer elution times. Complexes 1 to 4 were detected in plantlets exposed to the lowest concentration of $\mathrm{Al}(100 \mu \mathrm{M})$ as well, however variations in their relative concentrations were observed between plants exposed to $100 \mu \mathrm{M}$ and $400 \mu \mathrm{M}$ of $\mathrm{Al}$ (Fig. 1A and B). Monitoring of other elements during SEC-ICPMS measurements allowed determining that Fe co-elutes with the detected $\mathrm{Al}$ complexes 1 to 4 and that phosphor co-elutes with the complex detected in shoots (Fig. 1C and D; respectively). Oxalate is a well-described ligand for $\mathrm{Al}$ in accumulating plants, ${ }^{12}$ therefore an Al-oxalic acid standard solution was analyzed by SEC-ICP-MS. However, the elution time of the detected complex did not match any of the previously detected complexes, indicating that oxalate is not a major ligand for $\mathrm{Al}$ in P. almogravensis (Fig. S1A in the ESI $\dagger$ ).

High-resolution MS experiments were employed in an attempt to identify the Al-complexes occurring in P. almogravensis. Because the chromatographic separation provided by SEC is not sufficient to obtain precise MS measurements, the separation was conducted by HILIC. The Al species identified so far in accumulating plants are complexes with organic acids. HILIC is an adequate method for the separation of these complexes considering that the resins guarantee a strong retention of highly polar complexes and the corresponding buffers are compatible with ESI-MS. ${ }^{13}$ However, our results show that although a better resolved signal was obtained, as opposed to SEC, only one sharp Al peak could be detected after HILIC separation (Fig. 2). This result can be explained by the fact that the other minor complexes are eluting in less defined peaks because of a probably lower stability of these forms and higher interaction with chromatographic material. ${ }^{8}$

The obtained HILIC-ICP-MS chromatogram indicates the approximate retention time of the detected $\mathrm{Al}$-complex, however,

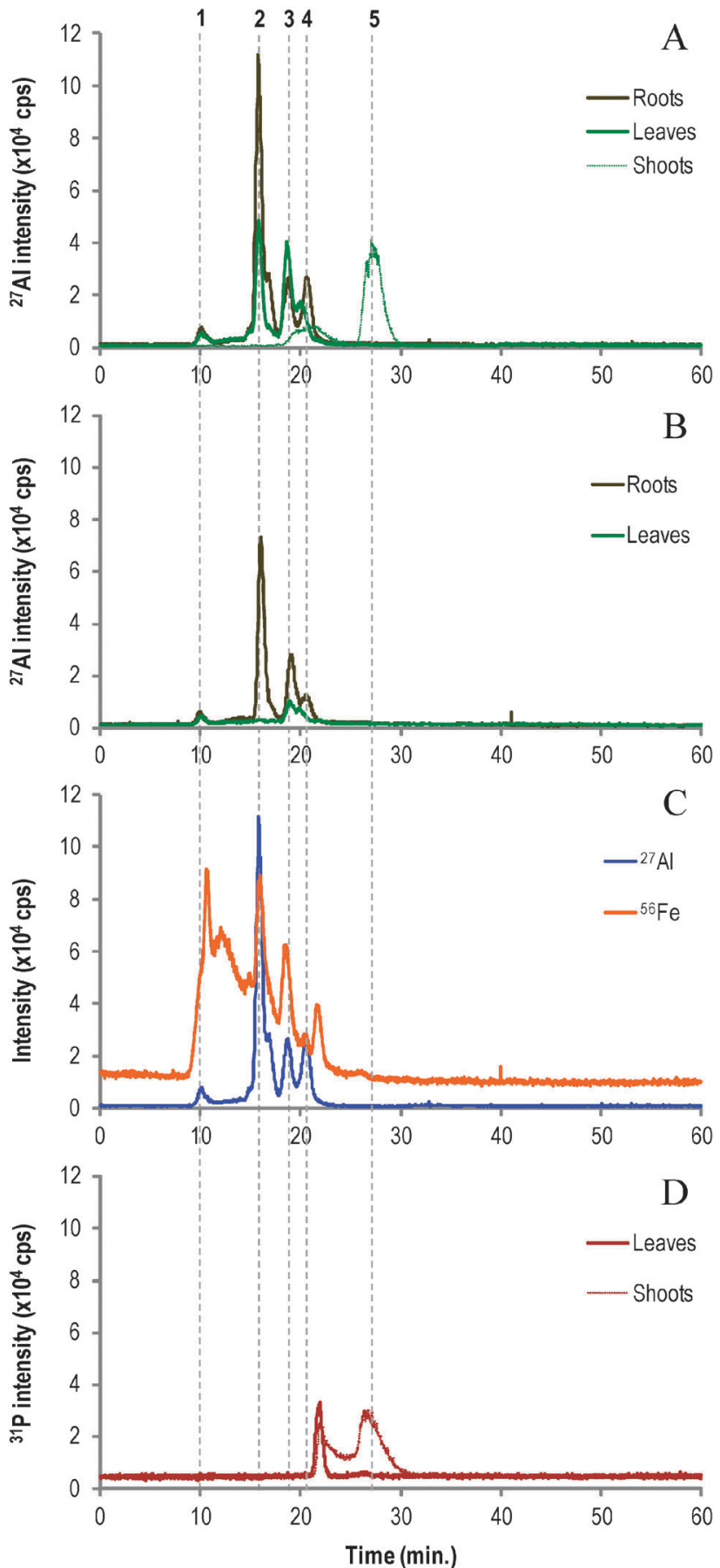

Fig. 1 SEC-ICP-MS chromatograms of $P$. almogravensis plants cultured in liquid Murashige and Shoog medium supplemented with Al: ${ }^{27} \mathrm{Al}$ signals detected in root, leaf and shoot samples exposed to $400 \mu \mathrm{M} \mathrm{Al}(\mathrm{A})$; root and leaf samples exposed to $100 \mu \mathrm{M} \mathrm{Al}(\mathrm{B}) ;{ }^{56} \mathrm{Fe}$ and ${ }^{27} \mathrm{Al}$ signals detected in the root sample exposed to $400 \mu \mathrm{M} \mathrm{Al}(\mathrm{C})$; and the ${ }^{31} \mathrm{P}$ signal detected in leaves and shoot samples exposed to $400 \mu \mathrm{M} \mathrm{Al}$ (D).

because $\mathrm{Al}$ is a mono-isotopic element it is not possible to examine the mass spectra obtained by HILIC-ESI-MS for molecular ions containing metals with specific isotopic signatures, as is the case for nickel ${ }^{13}$ and cadmium complexes ${ }^{14}$ for instance. A multitude of molecular ions is typically observed for 


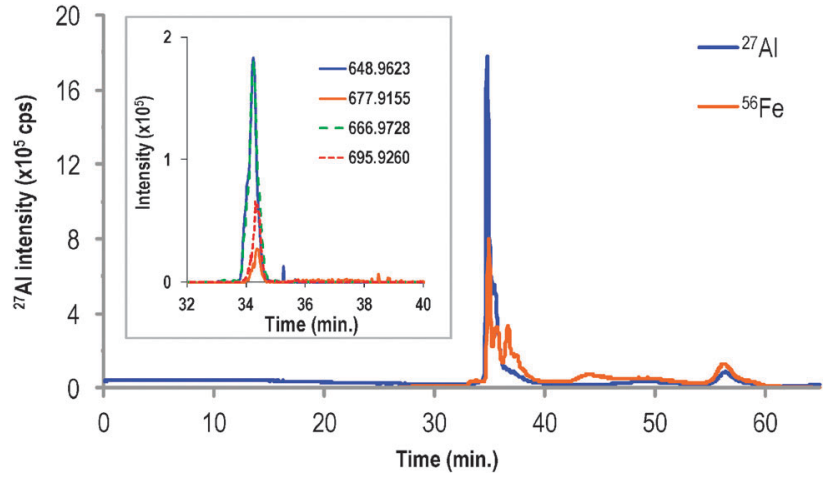

Fig. $2{ }^{27} \mathrm{Al}$ HILIC-ICP-MS chromatogram of the $P$. almogravensis root sample exposed to $400 \mu \mathrm{M}$ Al. Inset depicts the extracted ion chromatogram of $\mathrm{m} / \mathrm{z}$ $648.96,666.97,677.92$ and 695.93 ions obtained by HILIC-ESI-MS.

each specific retention time and it is therefore unfeasible to identify de novo an Al-bearing complex without additional information. This is one of the limitations when pursuing the identification of metal complexes of mono-isotopic elements, especially in samples for which no prior information is available. In our case, because the Al-complex detected after HILIC also co-elutes with Fe (Fig. 2), the MS spectra were examined for molecular ions bearing the characteristic isotopic pattern of $\mathrm{Fe}$ at the retention time of the detected Al-complexes (Fig. 3). Two molecular ions with exact masses of $\mathrm{m} / z 677.92$ and 695.93 were identified following this approach. Two other ions were observed at the same retention time with an exact mass difference of $\Delta$ $28.95 \mathrm{~m} / \mathrm{z}$, which corresponds to the difference in atomic weight between ${ }^{56} \mathrm{Fe}$ and ${ }^{27} \mathrm{Al}$. This result indicates that the $\mathrm{m} / \mathrm{z} 648.96$ and 666.97 molecular ions bear at least one $\mathrm{Al}$ atom and that it is interchangeable with Fe. Exact mass determination indicated that the $\mathrm{m} / \mathrm{z} 648.96$ and 666.97 molecular ions are consistent with a tri-Al tricitrate $\left(\mathrm{Al}_{3} \mathrm{Cit}_{3}\right)$ and an $\mathrm{Al}_{3} \mathrm{cit}_{3}+\mathrm{H}_{2} \mathrm{O}$ complex, respectively. The assignment of these complexes was confirmed by analyzing a standard solution of $\mathrm{Al}$ and citric acid under the same conditions (Fig. S2 in the ESI + ). This allowed for the assignment of the molecular ions at $\mathrm{m} / \mathrm{z} 677.92$ and 695.93 as $\mathrm{Al}_{2} \mathrm{Fecit}_{3}$ and $\mathrm{Al}_{2} \mathrm{Fecit}_{3}+\mathrm{H}_{2} \mathrm{O}$ (Fig. 3). Interestingly, the molecular ions corresponding to the $\mathrm{AlFe}_{2} \mathrm{cit}_{3}$ and $\mathrm{Fe}_{3} \mathrm{cit}_{3}$ complexes could also be detected at lower intensities (Fig. S3 in the ESI $\dagger$ ). An extracted ion chromatogram indicated that the identified tricitrate complexes have the same retention time as the Al-complex detected by HILIC-ICP-MS (inset Fig. 2). To confirm the role of citric acid in Al complexation, a citric acid-Al standard solution was analyzed by SEC-ICP-MS. The resulting chromatogram shows a very good match between the complexes 2, 3 and 4 from root extract and the $\mathrm{Al}$-citric acid standard solution (Fig. $1 \mathrm{~A}$ and Fig. S1B in the ESI $\dagger$ ) indicating that they are different forms of Al-citrate complexes, with $\mathrm{Al}_{3} \mathrm{cit}_{3}$ (peak 2) corresponding to the major peak as this complex was identified as the main $\mathrm{Al}$ complex by HILIC ESI MS. Regarding the remaining Al signals

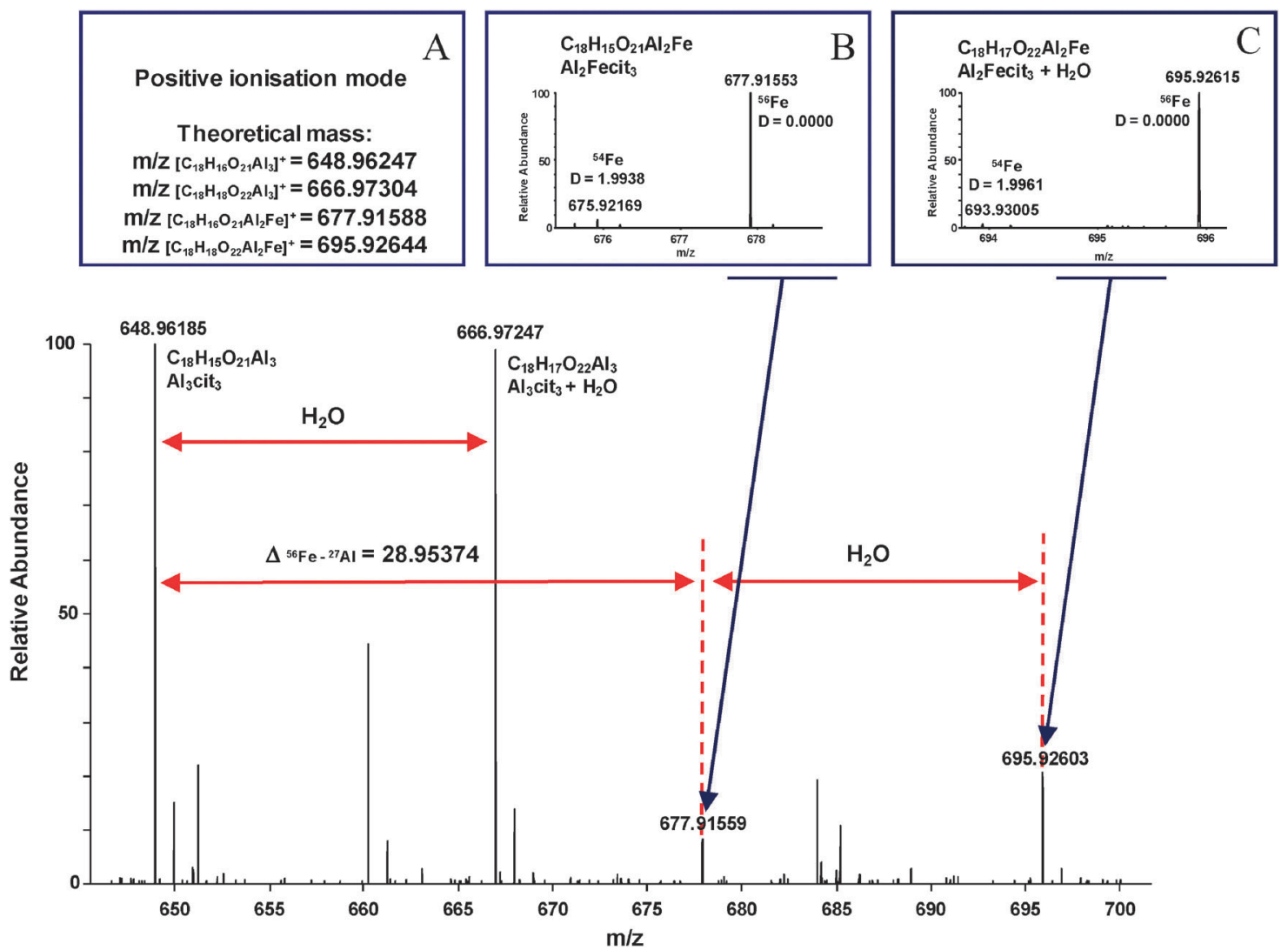

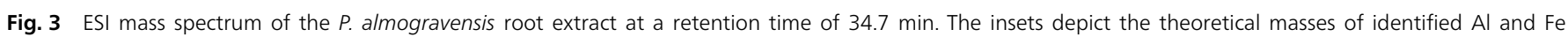
complexes in positive ionization mode $(A)$ and ions with a characteristic isotopic signature of iron (B and $C$ ). 


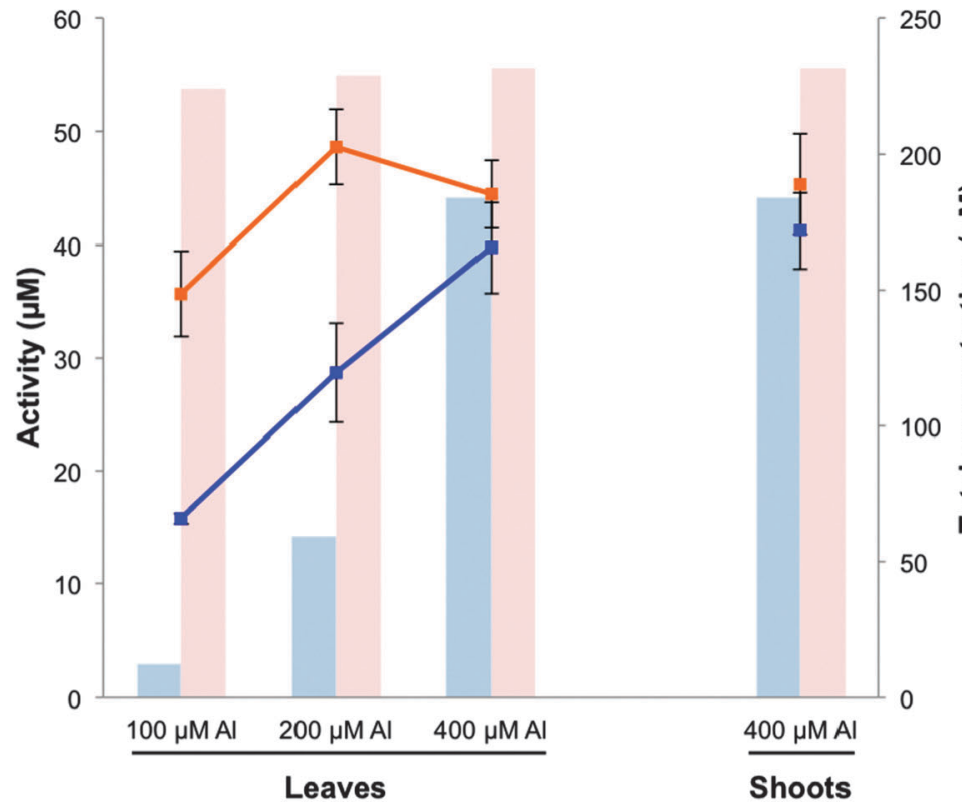

Fig. 4 Total Al and Fe concentration determination in leaves of $P$. almogravensis exposed to $\mathrm{Al}$ and calculated $\mathrm{Al}^{3+}$ and Fe $\mathrm{F}^{3+}$ activity in the respective culture solution. Activity values were predicted using the Geochem-EZ speciation program based on chemical equilibrium constants.

detected in Fig. 1, peak 1 corresponds to the void due the Al entrapped with high molecular weight biomolecules and nanoparticles while peak 5 (detected exclusively in shoots) is likely to correspond to $\mathrm{Al}$ phosphate (matching peak shapes and migration times between Fig. 1A and D).

The total concentration of $\mathrm{Al}$ and $\mathrm{Fe}$ was determined in leaf samples and plotted together with the calculated $\mathrm{Al}$ and $\mathrm{Fe}$ activity in the culture media (Fig. 4). According to Parker et al. ${ }^{15}$ the activity of a free uncomplexed metal is in most cases the most relevant parameter to determine plant responses to changes in nutrient solution composition. The low $\mathrm{pH}$ and reduced macronutrients concentration in culture media allowed obtaining a significant amount of free $\mathrm{Al}$ in solution (34.6\%, Table 1) because less $\mathrm{Al}$ is bound to $\mathrm{SO}_{4}$ and EDTA. Our results also demonstrate that the concentration of $\mathrm{Al}$ found in plantlet leaves is two orders of magnitude higher than the $\mathrm{Al}^{3+}$ activity in culture solution (Fig. 4), indicating that $P$. almogravensis is able to concentrate $\mathrm{Al}$ in its upper tissues. Also, the determination of total $\mathrm{Al}$ indicates that its uptake is concentration-dependent and that the uptake capacity has not reached saturation at $400 \mu \mathrm{M} \mathrm{Al}$ (Fig. 4).

Table 1 Speciation of $\mathrm{Al}$ and $\mathrm{Fe}$ in Murashige and Skoog medium with macronutrients reduced to one quarter supplemented with $400 \mu \mathrm{M} \mathrm{Al}$ at pH 4.0. Values were calculated using Geochem-EZ and are presented as a percentage of the total $\mathrm{Al}$ and Fe present in solution

\begin{tabular}{lcc}
\hline Species & $\mathrm{Al}^{3+}(\%)$ & $\mathrm{Fe}^{3+}(\%)$ \\
\hline Free & 34.60 & 92.38 \\
Complexed with: & & \\
$\mathrm{PO}_{4}$ & 27.67 & 3.96 \\
EDTA & 23.16 & 0.15 \\
$\mathrm{SO}_{4}$ & 12.18 & 2.64 \\
$\mathrm{OH}^{-}$ & 1.94 & 0
\end{tabular}

\section{Discussion}

\section{Identification of a tri-Al tricitrate complex following a mass spectrometry based approach}

This work reports the first direct and unequivocal identification of an Al-complex in an accumulating plant using ESI-MS without prior information. Al speciation studies in plants have been frustrated by the technical constraints limiting the separation and identification of $\mathrm{Al}$ complexes. ${ }^{16}$ The complex aqueous coordination chemistry of $\mathrm{Al}$, the lack of a suitable multiisotopic profile and the typical instability of metal complexes that renders concentration procedures unfeasible have slowed the understanding of the physiology of $\mathrm{Al}$ detoxification in tolerant plants. Most studies have been based on ${ }^{27} \mathrm{Al}$ NMR spectroscopy with a consequence that only plants accumulating extremely high concentrations could be examined. A 1:1 complex of $\mathrm{Al}$ and citrate has been detected in the xylem of several $\mathrm{Al}$ accumulating plants by ${ }^{27} \mathrm{Al}$ NMR spectroscopy. ${ }^{17} \mathrm{ESI}-$ MS experiments confirmed that in Hydrangea macrophylla cell sap an Al-citrate complex $(m / z 215)$ occurs. ${ }^{18}$ In this work we report that $\mathrm{Al}$ can be complexed by a tricitrate ligand. High-resolution MS experiments rendered a molecular ion at $648.96 \mathrm{~m} / \mathrm{z}$ after separation by hydrophilic interaction LC. Exact mass determination and comparison with an Al-citrate standard solution allowed assigning the complex as tri-Al tricitrate. This complex is the most stable one occurring in P. almogravensis as it remained intact after both HILIC and SEC separation. The structure of a tri-Al tricitrate complex obtained by chemical synthesis has been characterized by NMR spectroscopy and X-ray crystallography ${ }^{19}$ and a stability constant of 16.3 was determined by potentiometric studies, ${ }^{20}$ which indicates that it is a quite stable complex. The results obtained for fragmentation of the $\mathrm{m} / \mathrm{z} 648.96$ molecular ion after CID-MS experiments 
support to some extent that $\mathrm{Al}_{3} \mathrm{Cit}_{3}$ has the same structure, i.e., the loss of one citrate moiety could be observed indicating that the three $\mathrm{Al}$ atoms maintained in the central core were bound by the remaining two citrate molecules (Fig. S4 in the ESI $\dagger$ ). The absence of observed loss of aluminum ions during fragmentation indicates that the $\mathrm{Al}_{3}$ core is well buried into the complex as expected according to its structure. The knowledge that tricitrate is able to bind Al will allow determining parameters that are relevant to predict the fate of this complex in planta. Determination of stability constants and steric effects is important to predict to what extent the ligand prevents $\mathrm{Al}$ from binding to essential biomolecules, potential for membrane permeation and transport across the tonoplast that will determine the site of sequestration. Further investigation will have to be conducted to indicate the function of the tricitrate ligand regarding Al detoxification in $P$. almogravensis. It will be interesting to determine if the complex is used for transport only or if it can also be detected in intracellular spaces. $P$. almogravensis is a small woody hemicryptophyte that grows without a distinct stem, ${ }^{21}$ so it will be unfeasible to isolate xylem and conversely, xylem will always be analysed when taking the leaves as a whole. In order to determine if the complex is found in xylem alone, separate analysis of cellular structures (protoplasts and vacuoles) will be required. The best studied Al-accumulating plants so far (Fagopyrum esculentum, Camellia Sinensis and Melastoma malabathricum) and $P$. almogravensis are considerably distinct from a taxonomical perspective, yet the involvement of organic acids in Al-detoxification seems to be universal. Because $P$. almogravensis has an unusual ecological behaviour compared to most Al-accumulating plants, ${ }^{21}$ it was interesting to determine that $\mathrm{Al}$ is complexed by the organic acid citrate. The importance of organic acids in Al-detoxification might be explained by the high affinity of Al for electronegative donor groups like carboxyl but also due to the ubiquitous nature of these metabolites and the low metabolic investment that is required to synthesize them. ${ }^{22}$

\section{$\mathrm{Al}$ and $\mathrm{Fe}$ are complexed by tricitrate}

The relation between $\mathrm{Fe}$ and $\mathrm{Al}$ metabolism is interesting considering that $\mathrm{Fe}$ is essential for development and $\mathrm{Al}$ toxic for most plants, yet their similar chemical properties pose a significant challenge for selective uptake and incorporation into metabolism. ${ }^{23}$ More interestingly, a tri-Fe(III) tricitrate complex involved in Fe transport has been recently identified in xylem sap of tomato plants ${ }^{24}$ and our results show that $\mathrm{Fe}$ (III) and $\mathrm{Al}$ are interchangeable in this complex indicating that one of the ligands binding $\mathrm{Al}$ is the same ligand responsible for Fe transport. The Fe complex was modelled as having an oxobridged tri-Fe(III) $\left(\mathrm{Fe}_{3} \mathrm{Ocit}_{3}\right)$ core and owing to its compact molecular geometry it is expected to permeate the plasmodesmata directly. ${ }^{24}$ The authors also reported that while both $\mathrm{Fe}_{3} \mathrm{Cit}_{3}$ and $\mathrm{Fe}_{3} \mathrm{Ocit}_{3}$ complexes could be identified in Fe-citrate standard solutions, only $\mathrm{Fe}_{3} \mathrm{Ocit}_{3}$ was found in xylem samples. However, the $\mathrm{Fe}_{3} \mathrm{Cit}_{3}$ complex was detected in P. almogravensis root samples and represents the first report of this complex in biological samples (Fig. S3 in the ESI + ). The fact that, of the biologically relevant elements, Fe has the closest ionic radius to the one of $\mathrm{Al}$ might explain their binding by the same ligand considering that the ionic radius is one of the most important predictive parameters relating to the biological behavior of metal ions. $^{25}$ The relative concentration ratios between the $\mathrm{Al}-$ and Fe-complex determined using the relative ${ }^{27} \mathrm{Al}$ and ${ }^{56} \mathrm{Fe}$ signal intensities (depicted in Fig. 1C) combined with the sensitivity of the instrument for these isotopes and the fact that the estimated free activity of $\mathrm{Fe}$ in the culture medium supplemented with $400 \mu \mathrm{M}$ is higher than that of $\mathrm{Al}$ (Fig. 4) suggest that $\mathrm{Al}$ can outcompete $\mathrm{Fe}(\mathrm{III})$ for the tricitrate ligand. This observation has consequences concerning the effect of free $\mathrm{Al}$ concentration in soils on the $\mathrm{Fe}$ homeostasis in $P$. almogravensis. In fact, the results determined for the total $\mathrm{Fe}$ and $\mathrm{Al}$ concentrations indicate that the concentration of $\mathrm{Al}$ in the culture media affects the concentration of ${ }^{56} \mathrm{Fe}$ found in leaves (Fig. 4). While the concentration of ${ }^{56} \mathrm{Fe}$ increases when the concentration of $\mathrm{Al}$ in the culture solution is increased from $100 \mu \mathrm{M}$ to $200 \mu \mathrm{M}$, an increment of the $\mathrm{Al}$ concentration from $200 \mu \mathrm{M}$ to $400 \mu \mathrm{M}$ leads to a reduction in ${ }^{56} \mathrm{Fe}$ concentration. In fact, a reduction of $\mathrm{Fe}$ uptake as a result of $\mathrm{Al}$ supplementation was also observed in M. malabathricum. ${ }^{26}$ The authors observed that Al supplementation ameliorated Fe toxicity and speculated that, in M. malabathricum, the accumulation of $\mathrm{Al}$ could be an adaptive advantage to Fe-rich acid sulphate soils. The fact that $P$. almogravensis colonizes soils enriched in $\mathrm{Fe}$ and free $\mathrm{Al},{ }^{4}$ makes it an interesting model plant to study the interaction of the uptake of both metals. However, further experiments will have to point out to what extent $\mathrm{Al}$ can compete with $\mathrm{Fe}$ for binding with citrate and how it affects Fe uptake. A recent study on Fe uptake in Bacillus cereus demonstrated for the first time that a protein, FctC, could act as a specific binder for the $\mathrm{Fe}_{3} \mathrm{Cit}_{3}$ complex. ${ }^{27}$ Even if the structure of $\mathrm{Al}_{3} \mathrm{Cit}_{3}$ seems to be slightly different from the one of $\mathrm{Fe}_{3} \mathrm{Cit}_{3},{ }^{27}$ it could be hypothesized that similar proteins could occur in higher organisms such as plants and for other metal complexes such as $\mathrm{Al}_{3} \mathrm{cit}_{3}$.

\section{Speciation of $\mathrm{Al}$ is concentration-dependent}

The results presented in Fig. 1 indicate that $\mathrm{Al}$ speciation in $P$. almogravensis is dependent on internal concentration. The $\mathrm{Al}_{3} \mathrm{cit}_{3}$ complex (complex 2) was not detected in leaves of plants exposed to the lowest concentration of $\mathrm{Al}$ while it was detected in roots (Fig. 1B) and in leaves of plants exposed to $400 \mu \mathrm{M} \mathrm{Al}$ (Fig. 1A). The $\mathrm{Al}^{3+}$ cation has a great affinity for negatively charged pectin ${ }^{28}$ making it difficult to distinguish intracellular $\mathrm{Al}$ from $\mathrm{Al}$ adhered to the root cell wall. Therefore, instead of determining total concentration of $\mathrm{Al}$ in roots, a more precise measure of uptake is to consider the accumulation of $\mathrm{Al}$ in the upper organs. The quantification of total Al confirms that plants exposed to $400 \mu \mathrm{M} \mathrm{Al}$ accumulate more $\mathrm{Al}$ in leaves than plants exposed to $100 \mu \mathrm{M}(165.4 \pm 16.6 \mu \mathrm{M}$ and $65.8 \pm 1.8 \mu \mathrm{M}$, respectively). Shen et $a l^{29}$ reported that in buckwheat (F. esculentum) leaves different $\mathrm{Al}$ species were detected depending on the concentration of internal Al. At lower $\mathrm{Al}$ concentrations only $\mathrm{Al}$-oxalate was detected while at higher concentrations Al-citrate complexes could also be observed. In buckwheat, $\mathrm{Al}$ that is bound to citrate in xylem undergoes a 
ligand exchange in leaves, where it is converted to $\mathrm{Al}$-oxalate. The authors proposed that when oxalate is limiting Al-citrate cannot be converted to Al-oxalate completely and both complexes are therefore detected simultaneously. Considering that an Al-citrate complex also occurs in P. almogravensis, the observed results could be an indication that a similar ligand exchange process is present and that it is halted at higher internal $\mathrm{Al}$ concentrations. However, it is more likely that the speciation of $\mathrm{Al}$ is dependent on the internal $\mathrm{Al}$ : citrate ratio considering that complexes 3 and 4 are also citrate complexes and that no Al-oxalate complexes could be detected (Fig. S1 in the ESI $\dagger$ ). Also the Al-citrate speciation diagrams presented by Fukushima et al. ${ }^{19,27,30}$ show that at typical physiological pH values the speciation of $\mathrm{Al}$ is dependent on the $\mathrm{Al}$ : citrate ratio and the formation of $\mathrm{Al}_{3} \mathrm{cit}_{3}$ is favoured as the $\mathrm{Al}$ : citrate ratio increases. Our results are consistent with the predicted speciation diagrams as the intensity of peak 2 (corresponding to the $\mathrm{Al}_{3} \mathrm{cit}_{3}$ complex) increases drastically between the extract of leaves exposed to $100 \mu \mathrm{M} \mathrm{Al}$ (Fig. 1B) and $400 \mu \mathrm{M} \mathrm{Al}$ (Fig. 1A) as a result of increasing internal $\mathrm{Al}$ concentration (Fig. 4). Accordingly, it could also be hypothesized that peaks 3 and 4 could respectively be related to Alcit $_{2}$ and Alcit complexes, ${ }^{27}$ which would explain the presence of three main peaks in the Al-citric acid standard solution chromatogram (Fig. S1B, ESI $\dagger$ ).

Finally, as stated above, competition with Fe certainly occurs during $\mathrm{Al}$ homeostasis. Actually, even if the structures of $\mathrm{Al}_{3} \mathrm{Cit}_{3}$ and $\mathrm{Fe}_{3} \mathrm{Cit}_{3}$ complexes have some dissimilarities, ${ }^{27}$ they have comparable stability constants, ${ }^{31}$ which would clarify why $\mathrm{Al}$ and Fe seem to enter into competition when present at similar concentration levels (Fig. 4). The actual equilibrium between Al, Fe and citrate (and other minor ligands) is therefore related to the $\mathrm{Al}(\mathrm{III}): \mathrm{Fe}(\mathrm{III})$ : citrate ratio, to their total amount, to the $\mathrm{pH}$ and to the presence of competing metals/organic acids/salts in the different specific plant cell compartments, which means that further investigation would be needed to get a detailed and simultaneous view of $\mathrm{Al}$ and $\mathrm{Fe}$ speciation in $P$. almogravensis.

\section{P. almogravensis roots and the uptake of Al}

When cultured in vitro, $P$. almogravensis plants grow normally even in the absence of developed root systems. Consequently, the importance of the root system in the speciation of $\mathrm{Al}$ in the upper tissues could be examined. In terms of $\mathrm{Al}$ uptake, no differences were observed between plantlets and shoots, considering that similar amounts were quantified in leaves (165.4 $\pm 16.6 \mu \mathrm{M}$ in plantlets and $171.8 \pm 14.0 \mu \mathrm{M}$ in shoots; Fig. 4). Because the root systems were excised in shoots, the conducting vessels are directly exposed to the culture solution and $\mathrm{Al}$ uptake is a consequence of co-transport of culture solution driven by transpiration. The fact that shoots and plantlets accumulate the same amount of $\mathrm{Al}$ in leaves suggests that the root cell membrane does not pose a barrier to $\mathrm{Al}$ uptake. However, the speciation analysis provided interesting results. The obtained SEC-ICP-MS chromatograms showed that the complexes 1 to 4 were absent from shoot samples, yet a broad Al signal eluting at longer retention times was observed, suggesting that it is bound to a ligand with lower molecular weight. By comparing the elution time of this Al-complex with the signal of other elements a correlation was observed with ${ }^{31} \mathrm{P}$ (Fig. 1D). In fact, according to the calculated speciation values, over $25 \%$ of $\mathrm{Al}$ is complexed by $\mathrm{PO}_{4}$ in the culture solution (Table 1), suggesting that $\mathrm{Al}$ does not undergo chemical transformation once taken up by shoots. The fact that the ${ }^{31} \mathrm{P}$ signal detected in shoots at $26.2 \mathrm{~min}$ was not observed in plantlet leaves (Fig. 1D) supports the hypothesis that $\mathrm{Al}$ is taken up directly as an $\mathrm{AlPO}_{4}$ complex in shoots. The reason why $\mathrm{Al}$ found in shoots is not converted to $\mathrm{Al}_{3} \mathrm{cit}_{3}$ is unclear, considering that large amounts of citrate can be found in shoots ${ }^{6 a}$ and the $\mathrm{Al}_{3} \mathrm{cit}_{3}$ complex is formed spontaneously when $\mathrm{Al}$ and citrate are in solution. One hypothesis is that the $\mathrm{Al}_{3} \mathrm{cit}_{3}$ complex is formed at the roots because $\mathrm{Al}$ is absorbed as $\mathrm{Al}^{3+}$ and is available for binding with citrate. Information on the molecular form of $\mathrm{Al}$ that is able to permeate the plasma membrane is still fragmentary, but evidence has been presented indicating that $\mathrm{Al}^{3+}$ is the most membrane mobile species. ${ }^{32}$ Because it was not expected for plants to have specific transporters for a non-essential element, it was hypothesized that $\mathrm{Al}^{3+}$ could permeate divalent cation channels. ${ }^{25}$ However, a specific Al transporter named Nrat1 (Nramp aluminum transporter 1) was recently discovered in rice. ${ }^{33}$ The protein is located on the plasma membrane of root cells and is specific for the $\mathrm{Al}^{3+}$ cation. Therefore it is possible that in $P$. almogravensis $\mathrm{Al}$ is taken up as $\mathrm{Al}^{3+}$ as well and immediately complexed by citrate. The $\mathrm{Fe}_{3} \mathrm{cit}_{3}$ complex has been identified only recently, ${ }^{24}$ so it is yet unknown if it is a universal ligand for Fe transport in plants. If this is the case, the fact $\mathrm{Al}$-accumulation has only been described for a limited amount of plants indicates that the Al-permeability at roots seems to be the main difference between accumulating and non-accumulating plants.

\section{Conclusions}

An integrated mass spectrometry approach encompassing parallel LC ICP-MS and ESI-MS measurements using the Fe signal as an internal tracer in MS spectra allowed for the direct identification of the $\mathrm{Al}_{3} \mathrm{Cit}_{3}$ complex based on exact mass determination and retention time comparison. Our results also demonstrate that the same tricitrate ligand complexes $\mathrm{Al}$ and $\mathrm{Fe}$ and that the relation between $\mathrm{Al}$ accumulation and $\mathrm{Fe}$ homeostasis should be further investigated. In P. almogravensis, $\mathrm{Al}$ is mainly bound to complexes related to citrate, of which $\mathrm{Al}_{3} \mathrm{cit}_{3}$ is the major form. In a later stage the subcellular localization of these complexes will be crucial to better understand the mechanisms behind $\mathrm{Al}$ tolerance in $P$. almogravensis and in plants in general. The high sensitivity of the employed methodology allowed studying the speciation of $\mathrm{Al}$ using minute samples. Therefore it is envisioned that the described methodology may provide new insights not only into the mechanisms regarding $\mathrm{Al}$ tolerance because it provides a means to study the speciation of Al with greater organ specificity but it may also provide information about $\mathrm{Al}$ species occurring in susceptible plants and its relation to toxicity. 


\section{Acknowledgements}

The authors acknowledge support from the Portuguese Foundation for Science and Technology (FCT, project PTDC/AGR-AAM/ $102664 / 2008$ and the post-doc grant assigned to T. Grevenstuk SFRH/BPD/73293/2010).

\section{Notes and references}

1 L. V. Kochian, O. A. Hoekenga and M. A. Pineros, How do crop plants tolerate acid soils? - Mechanisms of aluminum tolerance and phosphorous efficiency, Annu. Rev. Plant Biol., 2004, 55, 459-493, DOI: 10.1146/Annurev.Arplant.55.031903.141655.

2 H. R. von Uexkull and E. Mutert, Global Extent, Development and Economic-Impact of Acid Soils, Plant Soil, 1995, 171, 1-15.

3 J. F. Ma, P. R. Ryan and E. Delhaize, Aluminium tolerance in plants and the complexing role of organic acids, Trends Plant Sci., 2001, 6, 273-278, DOI: 10.1016/S13601385(01)01961-6.

4 C. Branquinho, H. C. Serrano, M. J. Pinto and M. A. MartinsLoucao, Revisiting the plant hyperaccumulation criteria to rare plants and earth abundant elements, Environ. Pollut., 2007, 146, 437-443, DOI: 10.1016/J.Envpol.2006.06.034.

5 K. S. Walter and H. J. Gillet, IUCN Red List of Threatened Plants, IUCN - The World Conservation Union, Gland, Cambridge, 1998.

6 (a) N. Martins, S. Goncalves, P. B. Andrade, P. Valentao and A. Romano, Changes on organic acid secretion and accumulation in Plantago almogravensis Franco and Plantago algarbiensis Samp. under aluminum stress, Plant Sci., 2013, 198, 1-6, DOI: 10.1016/J.Plantsci.2012.09.001; (b) N. Martins, S. Goncalves and A. Romano, Metabolism and aluminum accumulation in Plantago almogravensis and $P$. algarbiensis in response to low $\mathrm{pH}$ and aluminum stress, Biol. Plant., 2013, 57, 6, DOI: 10.1007/s10535-012-0271-3.

7 H. Y. Xia and G. D. Rayson, Investigation of aluminum binding to a Datura innoxia material using Al-27 NMR, Environ. Sci. Technol., 1998, 32, 2688-2692, DOI: 10.1021/ Es980171s.

8 M. J. Keith-Roach, A review of recent trends in electrospray ionisation-mass spectrometry for the analysis of metalorganic ligand complexes, Anal. Chim. Acta, 2010, 678, 140-148, DOI: 10.1016/J.Aca.2010.08.023.

9 T. Murashige and F. Skoog, A Revised Medium for Rapid Growth and Bio Assays with Tobacco Tissue Cultures, Physiol. Plant., 1962, 15, 473-497, DOI: 10.1111/J.13993054.1962.Tb08052.X.

10 S. Goncalves, N. Martins and A. Romano, Micropropagation and conservation of endangered species Plantago algarbiensis and P. almogravensis, Biol. Plant., 2009, 53, 774-778, DOI: 10.1007/S10535-009-0142-8.

11 J. E. Shaff, B. A. Schultz, E. J. Craft, R. T. Clark and L. V. Kochian, GEOCHEM-EZ: a chemical speciation program with greater power and flexibility, Plant Soil, 2010, 330, 207-214, DOI: 10.1007/S11104-009-0193-9.
12 (a) J. F. Ma, S. Hiradate and H. Matsumoto, High aluminum resistance in buckwheat - II. Oxalic acid detoxifies aluminum internally, Plant Physiol., 1998, 117, 753-759, DOI: 10.1104/Pp.117.3.753; (b) A. Morita, O. Yanagisawa, S. Takatsu, S. Maeda and S. Hiradate, Mechanism for the detoxification of aluminum in roots of tea plant (Camellia sinensis (L.) Kuntze), Phytochemistry, 2008, 69, 147-153, DOI: 10.1016/J.Phytochem.2007.06.007; (c) T. Watanabe, S. Misawa and M. Osaki, Aluminum accumulation in the roots of Melastoma malabathricum, an aluminum-accumulating plant, Can. J. Bot., 2005, 83, 1518-1522, DOI: 10.1139/ B05-111.

13 L. Ouerdane, S. Mari, P. Czernic, M. Lebrun and R. Lobinski, Speciation of non-covalent nickel species in plant tissue extracts by electrospray Q-TOFMS/MS after their isolation by $2 \mathrm{D}$ size exclusion-hydrophilic interaction $\mathrm{LC}$ (SEC-HILIC) monitored by ICP-MS, J. Anal. At. Spectrom., 2006, 21, 676-683, DOI: 10.1039/B602689c.

14 L. Q. Chen, Y. F. Guo, L. M. Yang and Q. Q. Wang, SECICP-MS and ESI-MS/MS for analyzing in vitro and in vivo Cd-phytochelatin complexes in a Cd-hyperaccumulator Brassica chinensis, J. Anal. At. Spectrom., 2007, 22, 1403-1408, DOI: 10.1039/B707830g.

15 D. R. Parker, J. F. Pedler, Z. A. Ahnstrom and M. Resketo, Reevaluating the free-ion activity model of trace metal toxicity toward higher plants: experimental evidence with copper and zinc, Environ. Toxicol. Chem., 2001, 20, 899-906.

16 J. Scancar and R. Milacic, Aluminium speciation in environmental samples: a review, Anal. Bioanal. Chem., 2006, 386, 999-1012, DOI: 10.1007/S00216-006-0422-5.

17 (a) J. F. Ma and S. Hiradate, Form of aluminium for uptake and translocation in buckwheat (Fagopyrum esculentum Moench), Planta, 2000, 211, 355-360, DOI: 10.1007/ S004250000292; (b) J. F. Ma, S. Hiradate, K. Nomoto, T. Iwashita and H. Matsumoto, Internal detoxification mechanism of $\mathrm{Al}$ in hydrangea - Identification of $\mathrm{Al}$ form in the leaves, Plant Physiol., 1997, 113, 1033-1039; (c) A. Morita, H. Horie, Y. Fujii, S. Takatsu, N. Watanabe, A. Yagi and H. Yokota, Chemical forms of aluminum in xylem sap of tea plants (Camellia sinensis L.), Phytochemistry, 2004, 65, 2775-2780, DOI: 10.1016/J.Phytochem.2004.08.043; (d) T. Watanabe and M. Osaki, Influence of aluminum and phosphorus on growth and xylem sap composition in Melastoma malabathricum L, Plant Soil, 2001, 237, 63-70, DOI: 10.1023/A:1013395814958.

18 H. Hotta, Q. Wang, M. Fukuda, S. Aizawa, T. Umemura, K. Sekizawa and K. I. Tsunoda, Identification of aluminum species in an aluminum-accumulating plant, hydrangea (Hydrangea macrophylla), by electrospray ionization mass spectrometry, Anal. Sci., 2008, 24, 795-798, DOI: 10.2116/Analsci.24.795.

19 T. L. Feng, P. L. Gurian, M. D. Healy and A. R. Barron, Aluminum Citrate - Isolation and Structural Characterization of a Stable Trinuclear Complex, Inorg. Chem., 1990, 29, 408-411, DOI: 10.1021/Ic00328a013.

20 A. Lakatos, I. Banyai, P. Decock and T. Kiss, Timedependent solution speciation of the Al-III-citrate system: 
Potentiometric and NMR studies, Eur. J. Inorg. Chem., 2001, 461-469.

21 H. C. Serrano, M. J. Pinto, M. A. Martins-Loucao and C. Branquinho, How does an Al-hyperaccumulator plant respond to a natural field gradient of soil phytoavailable Al?, Sci. Total Environ., 2011, 409, 3749-3756, DOI: 10.1016/ J.Scitotenv.2011.06.036.

22 P. R. Ryan and E. Delhaize, The convergent evolution of aluminium resistance in plants exploits a convenient currency, Funct. Plant Biol., 2010, 37, 275-284, DOI: 10.1071/Fp09261.

23 M. Fujii, K. Yokosho, N. Yamaji, D. Saisho, M. Yamane, H. Takahashi, K. Sato, M. Nakazono and J. F. Ma, Acquisition of aluminium tolerance by modification of a single gene in barley, Nat. Commun., 2012, 3, 713, DOI: 10.1038/Ncomms1726.

24 R. Rellan-Alvarez, J. Giner-Martinez-Sierra, J. Orduna, I. Orera, J. A. Rodriguez-Castrillon, J. I. Garcia-Alonso, J. Abadia and A. Alvarez-Fernandez, Identification of a Tri-Iron(III), Tri-Citrate Complex in the Xylem Sap of IronDeficient Tomato Resupplied with Iron: New Insights into Plant Iron Long-Distance Transport, Plant Cell Physiol., 2010, 51, 91-102, DOI: 10.1093/Pcp/Pcp170.

25 L. V. Kochian, Cellular Mechanisms of Aluminum Toxicity and Resistance in Plants, Annu. Rev. Plant Physiol., 1995, 46, 237-260, DOI: 10.1146/Annurev.Arplant.46.1.237.

26 T. Watanabe, S. Jansen and M. Osaki, Al-Fe interactions and growth enhancement in Melastoma malabathricum and Miscanthus sinensis dominating acid sulphate soils, Plant, Cell Environ., 2006, 29, 2124-2132, DOI: 10.1111/J.13653040.2006.01586.X.

27 T. Fukushima, A. K. Sia, B. E. Allred, R. Nichiporuk, Z. R. Zhou, U. N. Andersen and K. N. Raymond, Bacillus cereus iron uptake protein fishes out an unstable ferric citrate trimer, Proc. Natl. Acad. Sci. U. S. A., 2012, 109, 16829-16834, DOI: 10.1073/Pnas.1210131109.

28 W. J. Horst, N. Schmohl, M. Kollmeier, F. Baluska and M. Sivaguru, Does aluminium affect root growth of maize through interaction with the cell wall - plasma membrane cytoskeleton continuum?, Plant Soil, 1999, 215, 163-174, DOI: 10.1023/A:1004439725283.

29 R. F. Shen, T. Iwashita and J. F. Ma, Form of Al changes with Al concentration in leaves of buckwheat, J. Exp. Bot., 2004, 55, 131-136, DOI: 10.1093/Jxb/Erh016.

30 (a) L. O. Ohman, Equilibrium and Structural Studies of Silicon(Iv) and Aluminum(III) in Aqueous-Solution .17. Stable and Metastable Complexes in the System H+-Al-3+Citric Acid, Inorg. Chem., 1988, 27, 2565-2570; (b) M. Clausen, L. O. Ohman and P. Persson, Spectroscopic studies of aqueous gallium(III) and aluminum(III) citrate complexes, J. Inorg. Biochem., 2005, 99, 716-726, DOI: 10.1016/J.Jinorgbio.2004.12.007.

31 R. B. Martin, Citrate Binding of $\mathrm{Al}^{3+}$ and $\mathrm{Fe}^{3+}$, J. Inorg. Biochem., 1986, 28, 181-187, DOI: 10.1016/01620134(86)80081-2.

32 G. J. Taylor, J. L. McDonald-Stephens, D. B. Hunter, P. M. Bertsch, D. Elmore, Z. Rengel and R. J. Reid, Direct measurement of aluminum uptake and distribution in single cells of Chara corallina, Plant Physiol., 2000, 123, 987-996, DOI: 10.1104/Pp.123.3.987.

33 J. X. Xia, N. Yamaji, T. Kasai and J. A. F. Ma, Plasma membrane-localized transporter for aluminum in rice, Proc. Natl. Acad. Sci. U. S. A., 2010, 107, 18381-18385, DOI: 10.1073/Pnas.1004949107. 